\title{
Assessment of the intestinal immune response in Giardia duodenalis experimentally infected rats using quantitative real-time PCR
}

\author{
Original Abeer E. Mahmoud ${ }^{1}$, Hanaa Y. Bakir ${ }^{1}$, Yasser M. Mohamed ${ }^{1}$, Mai B. Zaid ${ }^{1}$, \\ Mohamed A. El-Mokhtar² \\ Article
}

Departments of ${ }^{1}$ Medical Parasitology and ${ }^{2}$ Medical Microbiology and Immunology, Faculty of Medicine, Assiut University, Assiut, Egypt

\begin{abstract}
Background: Giardia duodenalis is a well-known intestinal parasite. The host immune response needs much effort to be clarified.

Objective: Evaluation of the transcriptional level of a panel of cytokines in intestinal tissue and assessing the correlation between these levels and cyst count.

Material and Methods: An experimental G. duodenalis infection was conducted in a rat model composed of twentyfive laboratory-bred, parasite-free male albino rats, divided into 10 for control group and 15 for infected group. Samples from intestinal tissues were collected to investigate interferon gamma (IFN- $\gamma$ ), tumor necrosis factor alpha (TNF- $\alpha$ ), interleukin-4 (IL-4) and interleukin-10 (IL-10) using quantitative real-time (qRT)-PCR.

Results: The gene expression levels of IFN- $\gamma$ showed up-regulation on day 7 post-infection (p.i) and reached the peak on day 14 p.i which coincided with the peak of the cyst output. The peak of the expression level of TNF- $\alpha$, IL-4, and IL-10 was on day 7 p.i. The correlation between cyst count and relative gene expression of pro-inflammatory cytokines showed a strong positive correlation. IL-10 relative gene expression level was moderately correlated, while IL-4 relative gene expression level was weakly correlated.

Conclusion: Results indicate that this infection triggers a mixed type of immune response with predominant participation of the pro-inflammatory cytokines. The balance between the pro-inflammatory and the anti-inflammatory cytokines is important in defining infection outcome.
\end{abstract}

Key Words: Experimental rat model, Giardia duodenalis, cyst, cytokines

Received: 17 December 2017 , Accepted: 13 January 2018

Corresponding Author: Yasser M. Mohamed, Tel.: 01001076816, E-mail: yassser_mokh@yahoo.com

ISSN: 1687-7942, Vol. 11, No. 2, August 2018

\section{INTRODUCTION}

Giardia duodenalis is a worldwide protozoan parasite that affects about 280 million individuals every year ${ }^{[1]}$. The heterogenicity in the clinical symptoms of giardiasis among infected individuals is attributed by many authors to the presence of different genotypes ${ }^{[2]}$.Various studies have confirmed the occurrence of considerable levels of infection resulting from oro-gastric inoculation of $G$. duodenalis cyst into albino rats with consistent infection rates using an inoculum size of $2.5 \times 10^{4}$ to $5 \times 10^{5[3,4]}$.

Regarding the evaluation of the immune response to $G$. duodenalis, it has been postulated that both innate and adaptive immune mechanisms are necessary ${ }^{[5]}$. Reported mechanisms of the innate immunity include production of antimicrobial peptides, nitric oxide, phagocytosis by macrophages, maturation, and migration of dendritic cells to the site of infection ${ }^{[6]}$. Earlier work on adaptive immunity observed the essential role of $\mathrm{CD} 4+\mathrm{T}$ cell ${ }^{[7]}$, immunoglobulin $\mathrm{A}^{[8]}$ and immunoglobulin $\mathrm{G}^{[9]}$. In terms of cytokines, Djamiatun and Faubert ${ }^{[10]}$ reported that G. muris infection in BALB/c mice resulted in secretion of IFN- $\gamma$, IL-4 and IL- 5 by spleen and Peyer's patch cells.

IFN- $\gamma$ mediates cellular immune response and enhances differentiation of naïve CD4+ $\mathrm{T}$ cells, lymphocyte recruitment, and prolonged activation in tissues ${ }^{[11]}$.This cytokine is important for the clearance of G. muris and considered as a master component of Th1 responses ${ }^{[5]}$. A murine study conducted by Goyal and Shukla ${ }^{[12]}$ demonstrated that Giardia-infected mice had elevated levels of both IFN- $\gamma$ and TNF- $\alpha$. Saghaug et al. ${ }^{[13]}$ found that cells expressing TNF- $\alpha$ were higher in individuals infected with Giardia duodenalis than in controls. Besides, it has been found that Giardia-derived antigens increased production of TNF- $\alpha^{[14]}$, which is the chief regulator of pro-inflammatory cytokine production ${ }^{[15]}$. As regards IL-4, this cytokine is useful in enhancing Th2 and suppressing Th1 differentiation ${ }^{[16]}$. Long et al. ${ }^{[17]}$ reported that the increasing production of IL-10 might counterbalance the inflammatory response during infection. 
In line with the evaluation of the immune response, the use of a reproducible, efficient and fast method to provide this precise assessment is extremely beneficial. Quantitative real time-PCR has been considered by many authors to be of great benefit for assessment of immune responses in giardiasis ${ }^{[18-21]}$ and leishmaniasis ${ }^{[22]}$; and is of greater sensitivity than many other procedures ${ }^{[23]}$. Despite all efforts made on this issue, the available knowledge about the mechanisms of the immune response to giardiasis is still unsatisfactory. Therefore, the aim of this study is to analyze the cytokine transcriptional level in the intestinal tissue and assess the correlation between these levels and G. duodenalis cyst count.

\section{MATERIALS AND METHODS}

Type of the study: This experimental study was started in July 2015 and ended in January 2016. Procedures were conducted in the Animal house and the Department of Medical Parasitology, Faculty of Medicine, Assiut University.

Experimental animals: Twenty-five laboratorybred, parasite-free male albino rats, aged 3-4 weeks, and weighing 100-150 g were used. The rats were obtained from Theodor Bilharz Research Institute, Egypt. They were kept under convenient conditions. All were free from any intestinal parasites as determined by microscopic examination of their stools for three successive days.

Stool samples: Stool samples positive for Giardia duodenalis cysts collected from laboratories in Assiut University Hospitals were concentrated and processed to obtain $2 \times 10^{5}$ cysts $/ \mathrm{ml}^{[4]}$.

Study design: Experimental animals were divided into a control group including 10 rats and an infected group including 15 rats. Animals were infected orally with 200,000 G. duodenalis cysts per rat suspended in 1 $\mathrm{ml}$ saline. Cysts in rats stools were individually counted and the rats were sacrificed on days $7,14,21,28,35$ p.i. Intestinal samples were taken from the duodeno-jejunal junction. RNA extraction, reverse transcription and qRTPCR were done to evaluate IFN- $\gamma$, TNF- $\alpha$, IL- 4 and IL-10 in the intestinal tissues.

Cyst counts: Fresh fecal pellets from each rat in the study groups, including the control group, were collected separately every day from day one p.i until day 21 p.i, weighed and examined for $G$. duodenalis cysts $^{[4]}$. Next, the positive samples were counted using a hemocytometer slide $^{[4]}$. Cyst excretion was calculated as the number of cysts per gram stool/day.

Tissue sample collection: Number (n) of rats sacrificed per day was 3 from the infected group and 2 from the control group. Rats were sacrificed on days 7 , $14,21,28,35$ p.i based on cyst output pattern ${ }^{[24]}$. Intestinal samples were taken from the duodeno-jejunal junction (about $2.5 \mathrm{~cm}$ from each sacrificed rat) and processed by repeated intestinal washing using saline. To allow RNA extraction, intestinal samples were stored in RNAlater ${ }^{\mathbb{B}}$ (Imgenex, USA, catalog No. 761040 ) at $-80^{\circ} \mathrm{C}$.

RNA extraction ${ }^{[25]}$ : Intestinal samples were lysed and homogenized using Trizol reagent in conjunction with Direct-zol ${ }^{\mathrm{TM}}$ RNA MiniPrep kit (Zymo Research Corporation, USA State, catalog No.R2050) to isolate total RNA from intestinal tissue. Ethanol was added to the sample, which was then processed through a column with a basal silica membrane to which RNA binds. Any genomic DNA was removed by using RNase-free DNase set (Qiagen, USA, catalog No. 79254). The elution of the purified total RNA was performed in RNase-free water (Qiagen, USA, catalog No. 129112). Total RNA concentrations were determined using a NanoDrop ${ }^{\mathbb{R}}$ (Epoch Microplate Spectrophotometer, Biotek, VA, USA).

Reverse transcription ${ }^{[25]}$ : By using SensiFAST ${ }^{\mathrm{TM}}$ cDNA Synthesis Kit (BiolineReagents Ltd London, UK), RNA samples were transcribed into cDNA needed for qRTPCR (according to manufacturer's instructions). Reactions were run on a thermal cycler (Veriti ${ }^{\circledR}$ 96-Well, The Applied Biosystems ${ }^{\circledR}$,USA State).

Quantitative real time PCR: All qRT-PCR reactions were performed using SYBR Green mastermix (SensiFAST ${ }^{\mathrm{TM}}$ SYBR Hi-ROX Kit, Bioline, London, UK). Four $\mu 1$ of single-stranded cDNA and amplification primers (Invitrogen, UK) were used with a total reaction volume of $20 \mu$ l. The real time reaction was carried out using the 7500 Fast Real-Time PCR System (Applied Biosystems ${ }^{\circledR}$, USA State) according to the following conditions: 1 cycle of 2 min at $95^{\circ} \mathrm{C}$ followed by forty cycles of denaturation (at $95^{\circ} \mathrm{C}$ for $25 \mathrm{sec}$ followed by an annealing and extension step at $60^{\circ} \mathrm{C}$ for $1 \mathrm{~min}$ ). Sequences of the primers used for qRT-PCR reactions ${ }^{[25]}$ are shown in table (1).

Table 1: Sequences of the primers used for qRT-PCR reactions

\begin{tabular}{lll}
\hline Cytokine & \multicolumn{1}{c}{ Sense } & \multicolumn{1}{c}{ Anti-sense } \\
\hline IFN- $\boldsymbol{\gamma}$ & GGACAACATACTGCTAACCGG & ATATTTCGGAGAGAGGTACA \\
TNF- $\boldsymbol{\alpha}$ & CCAGCTAGTTGTCATCCTGC & GTGATGTGGACTTGGACTCA \\
$\mathbf{I L - 4}$ & ACCACAGTCCATGAAATCAC & TCCACCACCCTGTTGCTGTA \\
$\mathbf{I L - 1 0}$ & ATGAGCACAGAAAGCATGATCCGC & TCCACCACCCTGTTGCTGTA \\
GAPDH (Reference gene) & ACCACAGTCCATGAAATCAC & TCCACCACCCTGTTGCTGTA \\
\hline
\end{tabular}


Analysis of qRT-PCR results was performed using the comparative cycle threshold method (comparative Ct method) or $\Delta \Delta \mathrm{Ct}$ method. This method calculates the fold change in the gene expression level of each target gene depending on the relative fold difference between an infected and control sample. As $\Delta \mathrm{Ct}=$ mean $\mathrm{Ct}$ of target gene- mean $\mathrm{Ct}$ of reference gene $(\mathrm{GAPDH}) . \Delta \Delta \mathrm{Ct}=\Delta \mathrm{Ct}$ of the infected sample $-\Delta \mathrm{Ct}$ of the control. Relative fold change in gene expression $=2^{-\Delta \Delta \mathrm{Ct}}$. All conditions were done in duplicates ${ }^{[26]}$.

Statistical analysis: All analyses were carried out using the statistical package of the social science SPSS version 20 software. Data were described by mean \pm standard deviation. Mann-Whitney test was used for unpaired comparisons and Wilcoxon for paired comparisons. Pearson test was used to detect the correlation coefficient between the relative immune gene expression and $G$. duodenalis cyst count. A two-tailed $P$-value was used; $P<0.05$ was considered statistically significant and $P<0.001$ was highly significant.

Ethical consideration: The experiments were conducted in the Animal House, Faculty of Medicine, Assiut University and approved by the Animal House Ethical Committee, Faculty of Medicine, Assiut University. Animal handling protocols were in accordance with the standard international guidelines by the National Institute of Health guide for the use and care of laboratory animals and the guidelines used in other Egyptian universities and research centers. All rats were maintained in pathogen-free insulators.

\section{RESULTS}

Cyst excretion pattern: All experimentally infected rats showed excreted cysts in their stool indicating that all rats were successfully infected. The cyst shedding was first detected on day 6 p.i with a peak on day 14 p.i.
Then, the cyst excretion rapidly decreased and reached an undetectable level on day 20 p.i (Figure 1).

Analysis of the intestinal immune response: This was done by analyzing the transcription levels of proinflammatory (IFN- $\gamma, \mathrm{TNF}-\alpha$ ) and anti-inflammatory cytokines (IL-4, IL-10) on days 7, 14, 21, 28, 35 p.i. On day 7 p.i, there was a high up-regulation level with statistical significance for both IFN- $\gamma$ (mean fold change $76.11 \pm 1.41$ ) and TNF- $\alpha$ (mean fold change 19.03 \pm 0.42 ). The anti-inflammatory cytokine, IL-4 showed high upregulation with statistical significance (mean fold change $36.76 \pm 0.49$ ), but IL-10 level showed slight up-regulation. On day 14 p.i, there was a predominant high up-regulation level of the pro-inflammatory cytokines with statistical significance (IFN- $\gamma$ mean fold change $90.51 \pm 0.57$, TNF- $\alpha$ mean fold change $17.75 \pm 0.35$ ) in comparison with the slight up-regulation of the anti-inflammatory cytokines. On day 21 p.i IFN- $\gamma$ level continued to be highly upregulated (mean fold change 50.21 \pm 1.63 ). IL-4 level showed slight up-regulation (mean fold change 1.6 \pm 0.14 ). Both TNF- $\alpha$ and IL-10 levels showed down-regulation. On day 28 p.i, IFN- $\gamma$ level was still significantly up-regulated (mean fold change 13.93 \pm 1.41 ). IL-10 level showed slight up-regulation. Both TNF-aand IL-4 levels were downregulated. On day 35 p.i, IFN- $\gamma$ level showed significant up-regulation. TNF- $\alpha$, IL-4, and IL-10 levels were downregulated (Table 2, Figure 2).

Correlation between the relative gene expression and Giardia duodenalis cyst count: This was analyzed using Pearson's correlation coefficient test. There was a highly significant, strong positive correlation between $G$. duodenalis cyst count and (IFN- $\gamma$, TNF- $\alpha$ ) gene expression level ( $\mathrm{r}=0.77$ and 0.75 , respectively). There was a weak positive correlation with IL-4 gene expression level $(\mathrm{r}=0.10)$, which was not significant. There was a significant, moderate positive correlation with IL-10 gene expression level $(\mathrm{r}=0.51)$ (Figure 3$)$.

Table 2: The mean fold change ( \pm standard deviation) of gene expression level of pro-inflammatory cytokines (IFN- $\gamma$, TNF- $\alpha$ ) and antiinflammatory cytokines (IL-4, IL-10), in the control and infected groups.

\begin{tabular}{lcccc}
\hline & $\begin{array}{c}\text { Pro-inflammatory } \\
\text { IFN- } \boldsymbol{\gamma}\end{array}$ & $\begin{array}{c}\text { cytokines } \\
\text { TNF- } \boldsymbol{\alpha}\end{array}$ & $\begin{array}{c}\text { Anti-inflammatory } \\
\text { IL-4 }\end{array}$ & $\begin{array}{c}\text { cytokines } \\
\text { IL-10 }\end{array}$ \\
\hline Control & $0.9 \pm 0.2$ & $1.07 \pm 0.3$ & $1.02 \pm 0.2$ & $1 \pm 0.14$ \\
Infected & & & $1.87 \pm 0.35^{* *}$ \\
Day 7 & $76.11 \pm 1.41^{* *}$ & $19.03 \pm 0.42^{* *}$ & $36.76 \pm 0.49^{* *}$ & $1.46 \pm 0.64$ \\
Day 14 & $90.51 \pm 0.57^{* *}$ & $17.75 \pm 0.35^{* *}$ & $5.1 \pm 0.92^{* *}$ & $0.97 \pm 0.35$ \\
Day 21 & $50.21 \pm 1.63^{* *}$ & $0.47 \pm 0.28^{* *}$ & $50.21 \pm 1.63^{* *}$ & $1 \pm 0.37$ \\
Day 28 & $13.93 \pm 1.41^{* *}$ & $0.48 \pm 0.07^{* *}$ & $13.93 \pm 1.41^{* *}$ & $0.48 \pm 0.14^{* *}$ \\
Day 35 & $4.14 \pm 1.98^{* *}$ & $0.3 \pm 0.12$ & $4.14 \pm 1.98^{* *}$ & \\
\hline
\end{tabular}

The mean fold change of each cytokine in the infected group is compared with that of the control. ${ }^{*} P$-value $<0.05,{ }^{* *} P$-value $<0.001$. 


\section{DISCUSSION}

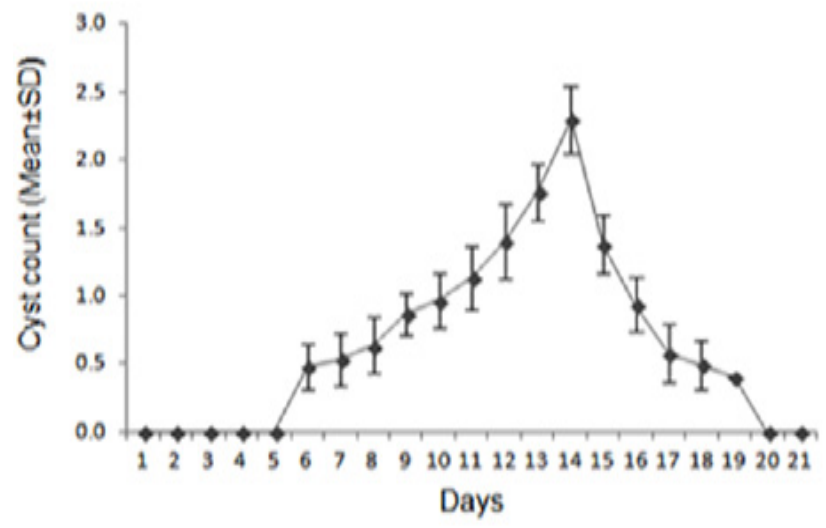

Fig. 1: Cyst excretion pattern in infected rats (with a peak on day 14 p.i). Each point on the graph represents the mean cyst output per gram feces for five animals \pm standard deviation (error bar).

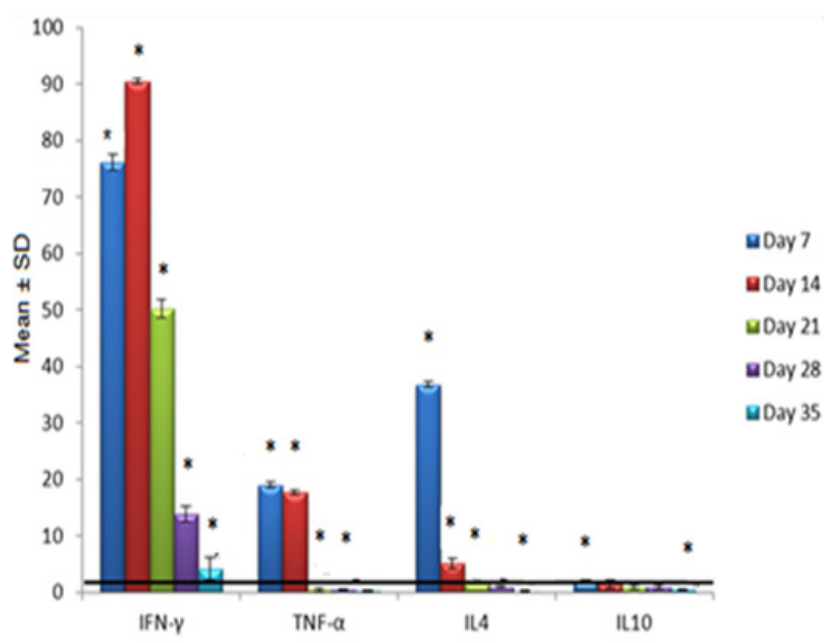

Fig. 2: Cytokines profile in the small intestine of $G$. duodenalis infected group using qRT-PCR. The mean fold changes in infected rats compared to controls (dark continuous line) are presented and standard deviations are shown as error bars. (IFN- $\gamma$ gene expression level was the highest one and reached the peak on day 14 p.i). ${ }^{*}$ The mean fold change of each cytokine in infected rats compared to the control.
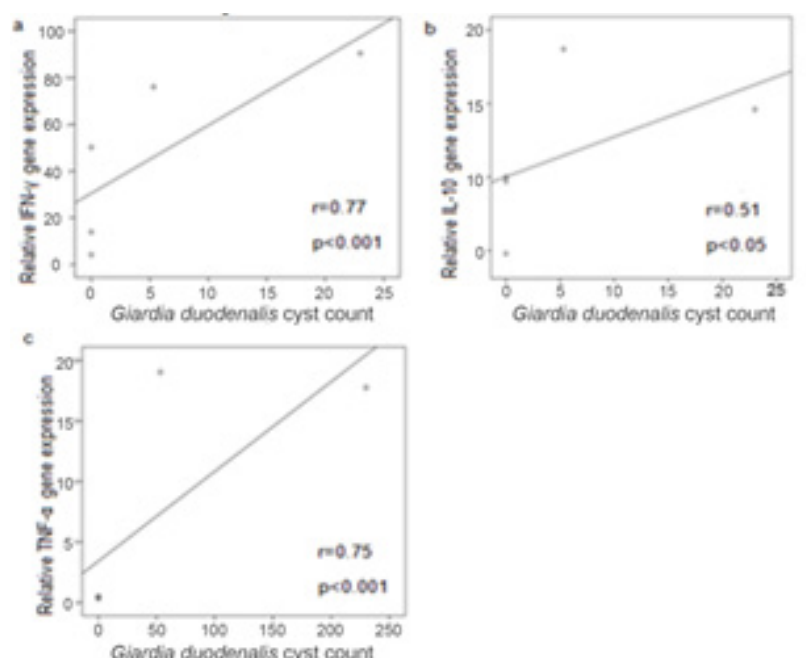

Fig. 3: Correlation between relative gene expression of IFN- $\gamma$ (a), IL-10 (b), TNF- $\alpha$ (c) and Giardia duodenalis cyst count (the relative gene expression of the pro-inflammatory cytokines, IFN- $\gamma$ and TNF- $\alpha$ showed a highly significant strong positive correlation) r: Pearson's rank correlation coefficient.
The establishment of an experimental study of giardiasis with subsequent use of immunological and molecular tools for analysis is helpful for explaining the immunopathogenesis that occurs in human disease. Despite being aware of $G$. duodenalis parasite and its effects on humans and animals, the ways the host'simmune system controls the infection and different cytokines related with this response are not fully understood ${ }^{[24]}$. These cytokines may have a role when designing new vaccines and drugs against this infection.

The current study observed that the number of cysts per gram in stool from infected rats was detected early in the infection with a peak on day 14 p.i. In addition, no cysts were detected by day 20 p.i (the third-week p.i). This pattern of infection was similar to that previously described by Jiménez et al. ${ }^{[24]}$. Contrary to our finding, Chen et al. ${ }^{[27]}$ and Dreesen et al. ${ }^{[21]}$ described the infection pattern with an early peak around day 6 p.i and the infection also ended by the third-week p.i. This difference may be due to variation in the immune status of the laboratory animals, parasite genotype, the infective dose and the type of animal $\operatorname{model}^{[28]}$

With regard to analysis of the intestinal immune response, our results demonstrated that IFN- $\gamma$ was the highest up-regulated cytokine. The gene expression level of IFN- $\gamma$ showed highly significant up-regulation in the early stage (day 7 p.i), reached the peak (day 14 p.i) and gradually decreased till the last stage (day $35 \mathrm{p} . \mathrm{i}$ ). It was argued that this pattern of expression would alarm the immune system in the early phase of inflammatory response to overcome the infection. Roxström-Lindquist et al. ${ }^{[5]}$ showed that this cytokine was important for the termination of $G$. muris infection and a master component of Th1 responses. In agreement with our results, a study conducted by Chen et al. ${ }^{[27]}$, reported an increase in the IFN- $\gamma$ intestinal level in $G$. duodenalis infected mice compared with the controls. Moreover, Jiménez et al. ${ }^{[24]}$ discovered that the stimulation of splenic cells of $G$. duodenalis infected mice with Giardia excretory-secretory antigens resulted in an increase in IFN- $\gamma$ level with a peak on day 14 p.i, followed by gradual reduction.

Another important pro-inflammatory cytokine, TNF- $\alpha$, was examined in the current study. We found that the gene expression level of TNF- $\alpha$ showed highly significant upregulation till day 14 p.i and down-regulation at succeeding time points (highly significant only on days $21,28 \mathrm{p}$.i). We found that the expression pattern of TNF- $\alpha$ might augment and act synergistically with IFN- $\gamma$ production especially at the early phase of the infection. Zhou et al.$^{[29]}$ demonstrated that this cytokine was necessary for defining the outcome of infection with $G$. duodenalis in mice (parasite burden and duration of the infection). In addition, the important role of TNF- $\alpha$ in early control of Giardia infection was reported by Matowicka-Karna et al. ${ }^{[30]}$. 
In the present study, the gene expression level of an essential anti-inflammatory cytokine IL-4 showed highly significant up-regulation on day 7 p.i. followed by a gradual decrease until day 21 p.i. Then it showed down-regulation at the succeeding time points (highly significant only on day 35 p.i). We believed that the expression pattern of IL-4, especially in the early phase, might have a balancing effect to overcome the high production level of both IFN- $\gamma$ and TNF- $\alpha$. Djamiatun and Faubert ${ }^{[10]}$ reported that G. muris infection in BALB/c mice resulted in secretion of IL-4 by spleen and Peyer's patch cells. In line with the results of the present study, Jiménez et al. ${ }^{[24]}$ observed that splenic cells stimulated by $G$. duodenalis excretory-secretory antigens produced an increased level of IL-4 with a peak on day 7 p.i followed by reduction.

Furthermore we observed that the gene expression level of IL-10 showed up-regulation on days 7, 14, 28 (highly significant only on day 7 p.i) and down-regulation at succeeding time points (highly significant only on day 35 p.i). Such an expression pattern supported our hypothesis on the balancing effect of anti-inflammatory cytokines (IL-4, IL-10) in the early phase to control the high production of pro-inflammatory cytokines (IFN- $\gamma$, TNF- $\alpha$ ) and decrease pathology. Regarding the role of IL-10 in giardiasis, Saghaug et al.$^{[13]}$ reported the increase of IL-10 in the culture supernatant of cells stimulated by the soluble protein of $G$. duodenalis assemblage A. Other regulatory anti-inflammatory responses have also been observed in G. duodenalis infection in calves ${ }^{[23]}$.

The correlation between $G$. duodenalis cyst count and the relative gene expression of the pro-inflammatory cytokines showed a highly significant strong positive correlation. Anti-inflammatory cytokines, IL-10 and IL-4 gene expression levels were moderately and weakly correlated with $G$. duodenalis cyst count, respectively. These results are in harmony with our belief, as the increasing numbers of Giardia cysts indicated persistent infection and inflammation which, in turn, enhanced the production of pro-inflammatory cytokines (IFN- $\gamma$ and TNF- $\alpha$ ). However, moderate and weak correlations were found with anti-inflammatory cytokines (IL-10, IL-4, respectively), as the infection and inflammation started to be controlled. As far as we know, the available literature about the correlation between $G$. duodenalis cyst count and the cytokines gene expression level is limited. To the best of our knowledge, the current study is one of the first studies on this issue. Holopainen et al. ${ }^{[31]}$ demonstrated a strong correlation between the increasing count of the virus and the pro-inflammatory cytokines gene expression levels in epithelioma-papulosum cyprini cells.

The results of the present study are consistent with those of Bayraktar et al.$^{[32]}$ and Ribeiro-Romão et al. ${ }^{[22]}$ as we found that the recorded profile of cytokines revealed the presence of a mixed type of immune response (Th1 and Th2 cytokines) and the dominant production level related to Th1 cytokines (IFN- $\gamma$ and TNF- $\alpha$ ). A study conducted by Singer and $\operatorname{Nash}^{[7]}$ disagreed with our results as they reported that neither a specific Th1 nor a specific Th2 response seem to be necessary for giardiasis.

On the whole, our results suggested that these cytokines participated in the early control of G. duodenalis infection and showed similarity with the cytokine profile reported by Jiménez et al. ${ }^{[24]}$ and their effect on the rapid elimination of the infection within 3 weeks after infection. On the other hand, Kamda and Singer ${ }^{[33]}$ reported the predominance of the anti-inflammatory state and subsequent chronicity of giardiasis, which is defined as giardiasis associated with the presence of parasites in the gut for more than 2 months ${ }^{[34]}$. Discrepancy in the results between the previously mentioned study and our study may be due to difference in the genotype of G. duodenalis used in each. Such wide variance was well illustrated by the results of some studies which demonstrated that infection with $G$. duodenalis assemblage B was associated with inflammation in human intestinal mucosa and produced pro-inflammatory cytokines including TNF- $\alpha^{[35]}$. Other authors demonstrated that assemblage A induced an anti-inflammatory state. Another explanation is the diversity in activation of dendritic cells and its subsequent function following exposure to different $G$. duodenalis assemblages ${ }^{[36]}$. Furthermore, each $G$. duodenalis genotype suggested the induction of a certain macrophage phenotype (pro-inflammatory M1 phenotype or anti-inflammatory M2 phenotype) that may significantly affect subsequent results of the infection ${ }^{[36,37]}$. Antigenic variation between the different genotypes may also contribute to the differences of the cytokine production patterns ${ }^{[38]}$. It is worth mentioning that the immune status of the host and the presence of associated diseases such as inflammatory bowel disease may also have an effect ${ }^{[39,40]}$.

\section{CONCLUSION}

To sum up, the current study emphasized the role of qRT-PCR in the precise assessment of gene expression level of the targeted cytokines. Applying this assay enabled us to demonstrate that giardiasis triggered both Th1 (proinflammatory cytokines) and Th2 (anti-inflammatory cytokines) response with predominance of the proinflammatory cytokines role. The balance between these cytokines and the timing of their production was crucial in $G$. duodenalis immune response to determine infection outcomes. Further studies are required to elucidate the capability of different $G$. duodenalis genotypes to stimulate different panels of pro-inflammatory and antiinflammatory cytokines and hence affect infection results. Taking these cytokines into consideration for the design of effective vaccines and new drugs is also recommended.

Author contribution: All authors equally contributed.

Acknowledgements: The study was funded by a research grant from the Grant Office, Faculty of Medicine, 
Assiut University, under grant no. (1570). The authors acknowledge with thanks the Grant Office for technical and financial support.

\section{CONFLICT OF INTEREST:}

The authors claimed no conflict of interest.

\section{REFERENCES}

1. Hagen KD, Hirakawa MP, House SA, Schwartz CL, Pham JK, Cipriano MJ et al. Novel structural components of the ventral disc and lateral crest in Giardia intestinalis. PLoS Negl Trop Dis 2011; 5(12):e1442.

2. Homan WL, Mank TG. Human giardiasis: genotype linked differences in clinical symptomatology. Int $\mathrm{J}$ Parasitol 2001; 31(8):822-826.

3. Mahmood S, Kaur K, Mittal N, Mahmood A. Giardia duodenalis: Expression of alkaline phosphatase activity in infected rat intestine. Exper Parasitol 2005; 110(2):91-95.

4. Mahmoud A, Attia R, Safaa S, Ibraheim Z. Ginger and cinnamon: can this household remedy treat giardiasis? Parasitological and histopathological studies. Iran J Parasitol 2014; 9(4):530-540.

5. Roxström-Lindquist $\mathrm{K}$, Palm D, Reiner D, Ringqvist E, Svärd SG. Giardia immunity-an update. Trends Parasitol 2006; 22(1):26-31.

6. Solaymani-Mohammadi S, Singer SM. Giardia duodenalis: the double-edged sword of immune responses in giardiasis. Exper Parasitol 2010; 126(3):292-297.

7. Singer SM, Nash TE. T-cell-dependent control of acute Giardia duodenalis infections in mice. Infect Immun 2000; 68(1):170-175.

8. Langford TD, Housley MP, Boes M, Chen J, Kagnoff MF, Gillin F et al. Central importance of immunoglobulin A in host defense against Giardia spp. Infect Immun 2002; 70(1):11-18.

9. Stark D, Barratt JLN, Van Hal S, Marriott D, Harkness J, Ellis JT. Clinical significance of enteric protozoa in the immunosuppressed human population. Clin Microbiol Rev 2009; 22(4):634-650.

10. Djamiatun K, Faubert GM. Exogenous cytokines released by spleen and Peyer's patch cells removed from mice infected with Giardia muris. Parasite Immunol 1998; 20(1):27-36.
11. Hill N, Sarvetnick N. Cytokines: promoters and dampeners of autoimmunity. Curr Opin Immunol 2002; 14(6):791-797.

12. Goyal N, Shukla G. Probiotic Lactobacillus rhamnosus GG modulates the mucosal immune response in Giardia intestinalis-infected BALB/c mice. Dig Dis Sci 2013; 58(5):1218-1225.

13. Saghaug CS, Sornes S, Peirasmaki D, Svard S, Langeland N, Hanevik K. Human memory CD4+ T cell immune responses against Giardia duodenalis. Clin Vaccine Immunol 2015; 23(1):11-18.

14. Ma TY, Iwamoto GK, Hoa NT, Akotia V, Pedram A, Boivin MA. TNF-alpha-induced increase in intestinal epithelial tight junction permeability requires NFkappa B activation. Am J Physiol Gastrointest Liver Physiol 2004; 286(3):367-376.

15. Parameswaran N, Patial S. Tumor necrosis factoralpha signaling in macrophages. Crit Rev Eukaryot Gene Expr 2010; 20(2):87-103.

16. Luzina IG, Keegan AD, Heller NM, Rook GAW, SheaDonohue T, Atamas SP. Regulation of inflammation by interleukin-4: a review of alternatives. J Leukoc Biol 2012; 92(4):753-764.

17. Long KZ, Rosado JL, Santos JI, Haas M. Associations between mucosal innate and adaptive immune responses and resolution of diarrheal pathogen infections. Infect Immun 2010; 78(3):1221-1228.

18. Roxström-Lindquist K, Ringqvist E, Palm D, Svärd S. Giardia duodenalis-induced changes in gene expression in differentiated Caco-2 human intestinal epithelial cells. Infect Immun 2005; 73(12):82048208.

19. Dreesen L, Rinaldi M, Chiers K, Li R, Geurden T, Van de Broeck W, et al. Microarray analysis of the intestinal host response in Giardia duodenalis assemblage E infected calves. Plos one 2012; 7(7):e40985.

20. Tako EA, Hassimi MF, Li E, Singer SM. Transcriptomic analysis of the host response to Giardia duodenalis infection reveals redundant mechanisms for parasite control. MBio 2013; 4(6).

21. Dreesen L, De Bosscher K, Grit G, Staels B, Lubberts $\mathrm{E}$, Bauge $\mathrm{E}$ et al. Giardia muris infection in mice is associated with a protective interleukin 17A response and induction of peroxisome proliferator-activated receptor alpha. Infect Immun 2014; 82(8):3333-3340.

22. Ribeiro-Romão RP, Saavedra AF, Da-Cruz AM, Pinto EF, Moreira OC. Development of real-time PCR 
assays for evaluation of immune response and parasite load in golden hamster (Mesocricetus auratus) infected by Leishmania (Viannia) braziliensis. Parasit Vectors 2016; 9(1):361.

23. Grit GH, Devriendt B, Van Coppernolle S, Geurden $\mathrm{T}$, Hope J, Vercruysse $\mathrm{J}$ et al. Giardia duodenalis stimulates partial maturation of bovine dendritic cells associated with altered cytokine secretion and induction of $\mathrm{T}$ cell proliferation. Parasite Immunol 2014; 36(4):157-169.

24. Jiménez JC, Fontaine J, Creusy C, Fleurisse L, Grzych $\mathrm{JM}$, Capron $\mathrm{M}$ et al. Antibody and cytokine responses to Giardia excretory/secretory proteins in Giardia intestinalis-infected $\mathrm{BALB} / \mathrm{c}$ mice. Parasitol Res 2014; 113(7):2709-2718.

25. Bakir HY, Tomiyama C, Abo Tu. Cytokine profile of murine malaria: stage-related production of inflammatory and anti-inflammatory cytokines. Biomed Res 2011; 32(3):203-208.

26. Livak KJ, Schmittgen TD. Analysis of relative gene expression data using real-time quantitative PCR and the 2- CT method. Methods 2001; 25(4):402-408.

27. Chen TL, Chen S, Wu HW, Lee TC, Lu YZ, Wu LL et al. Persistent/gut barrier damage and commensal bacterial influx following eradication of Giardia infection in mice. Gut Pathog 2013; 5:26.

28. Faubert G. Immune response to Giardia duodenalis. Clin Microbiol Rev 2000; 13(1):35-54.

29. Zhou P, Li E, Shea-Donohue T, Singer SM. Tumor necrosis factor $\alpha$ contributes to protection against Giardia duodenalis infection in mice. Parasite Immunol 2007; 29(7):367-374.

30. Matowicka-Karna J, Dymicka-Piekarska V, Kemona H. IFN-gamma, IL-5, IL-6 and IgE in patients infected with Giardia intestinalis. Folia Histochem Cytobiol 2009; 47(1):93-97.

31. Holopainen R, Tapiovaara H, Honkanen J. Expression analysis of immune response genes in fish epithelial cells following rana virus infection. Fish Shellfish Immunol 2012; 32(6):1095-1105.

32. Bayraktar MR, Mehmet N, Durmaz R. Role of IL2, IL-4 and IL-10 in patients infected with Giardia duodenalis. Acta Parasitologica Turcica 2005; 29:160-162.

33. Kamda JD, Singer SM. Phosphoinositide 3-kinasedependent inhibition of dendritic cell interleukin-12 production by Giardia duodenalis. Infect Immun 2009; 77(2):685-693.

34. Escobedo AA, Hanevik K, Almirall P, Cimerman S, Alfonso M. Management of chronic Giardia infection. Expert Rev Anti Infect Ther 2014; 12(9):1143-1157.

35. Lee HY, Hyung S, Lee NY, Yong TS, Han SH, Park SJ. Excretory-secretory products of Giardia duodenalis induce interleukin-8 production in human colonic cells via activation of p38, ERK1/2, NF-kappaB and AP-1. Parasite Immunol 2012; 34(4):183-198.

36. Cotton JA, Amat CB, Buret AG. Disruptions of host immunity and inflammation by Giardia duodenalis: potential consequences for cCo-infections in the gastro-intestinal Tract. Pathogens 2015; 4(4):764-792.

37. Mills CD, Kincaid K, Alt JM, Heilman MJ, Hill AM. M-1/M-2 macrophages and the Th1/Th2 paradigm. J Immunol 2000; 164(12):6166-6173.

38. Solaymani-Mohammadi S, Singer SM. Host immunity and pathogen strain contribute to intestinal disaccharidase impairment following gut infection. J Immunol 2011; 187(7):3769-3775.

39. Buhner S, Buning C, Genschel J, Kling K, Herrmann D, Dignass A et al. Genetic basis for increased intestinal permeability in families with Crohn's disease: role of CARD15 3020insC mutation. Gut 2006; 55(3):342347.

40. Rizzo A, Monteleone I, Fina D, Stolfi C, Caruso $\mathrm{R}$, Fantini MC et al. Inhibition of colitis by IL-25 associates with induction of alternatively activated macrophages. Inflamm Bowel Dis 2012; 18(3): 449-459. 